\title{
J.G.Farrell in his Own Words, Selected Letters and Diaries
}

\section{Elisabeth Delattre}

\section{(2) OpenEdition}

Journals

\section{Édition électronique}

URL : https://journals.openedition.org/etudesirlandaises/3234

DOI : 10.4000/etudesirlandaises.3234

ISSN : 2259-8863

\section{Éditeur}

Presses universitaires de Caen

\section{Édition imprimée}

Date de publication : 30 octobre 2012

Pagination : 174-175

ISBN : 978-7535-2158-2

ISSN : 0183-973X

\section{Référence électronique}

Elisabeth Delattre, «J.G.Farrell in his Own Words, Selected Letters and Diaries ». Études irlandaises [En ligne], 37-2 | 2012, mis en ligne le 30 octobre 2012, consulté le 06 août 2022. URL : http:// journals.openedition.org/etudesirlandaises/3234; DOI : https://doi.org/10.4000/etudesirlandaises. 3234

Ce document a été généré automatiquement le 6 août 2022.

\section{(c)}

Creative Commons - Attribution - Pas d'Utilisation Commerciale - Partage dans les Mêmes Conditions 4.0 International - CC BY-NC-SA 4.0

https://creativecommons.org/licenses/by-nc-sa/4.0/ 


\title{
J.G.Farrell in his Own Words, Selected Letters and Diaries
}

\author{
Elisabeth Delattre
}

\section{RÉFÉRENCE}

Lavinia GREACEN (ed.) : J.G.Farrell in his Own Words, Selected Letters and Diaries. Cork

University Press, 2009, XIII+464 p., ISBN 978-185918-428-8, €39

1 Dans l'avant-propos de cet ouvrage dont la publication coïncide avec le trentième anniversaire de la mort accidentelle et prématurée de James Gordon Farrell dans la baie de Bantry, John Banville décrit l'auteur de Troubles en ces termes : « Jim Farrell the man was immensely attractive, tall and slender and possessed of a slightly jaded and even slightly sinister elegance ». Certes, il ne pouvait laisser indifférents ceux, ou celles, qui eurent l'occasion de croiser sa route, même de manière fugitive. Après avoir publié en 1999 une biographie de l'écrivain, J.G.Farrell - the Making of a Writer, Lavinia Greacen s'est consacrée cette fois-ci à un minutieux travail de recherche de la correspondance adressée par le romancier à ses parents, ses ami(e)s plus ou moins proches et ses éditeurs.

Comme l'indique cette dernière dans sa brève introduction, certains passages ou certains patronymes ont été omis, par souci de discrétion. Classées par ordre chronologique, entrecoupées de notes prises par Farrell durant ses voyages en Inde et à Singapour notamment, mais aussi illustrées par des photographies de qualité, ces lettres permettent de retracer le cheminement d'un écrivain depuis des débuts difficiles jusqu'à la maturité et une aisance financière relative apportée par le Prix Booker obtenu en 1973. Il est vrai que les trois premiers romans n'eurent pas le succès escompté. Ils furent écrits pour la plupart en France, où Farrell occupa pendant plusieurs années des postes d'assistant en lycée, et où il aurait aimé pouvoir s'installer de manière permanente, même si ce qualificatif paraît un peu exagéré dans le cas de l'éternel nomade qu'il était. Une dernière lettre, par ailleurs photocopiée sous sa forme 
manuscrite, pleine d'espoir et adressée à l'éditrice de son dernier roman laissé inachevé, est datée de la veille de sa mort.

3 Les relations parfois conflictuelles de Farrell avec son entourage sont sans doute à mettre au compte d'une volonté farouche de se consacrer entièrement à son art, mais révèlent aussi un certain déchirement, ou désarroi devant les aléas de la vie, notamment la maladie dont les séquelles ne le quittèrent jamais vraiment. De très nombreuses notes explicatives placées à la suite de ces écrits, ainsi qu'un index et une chronologie de sa vie viennent utilement accompagner cette " voix autobiographique » particulière, qualifiée d'« educated drawl » par Lavinia Greacen. On mentionnera aussi la présence du magnifique poème, "A Disused Shed in Co. Wexford ", que Derek Mahon avait dédié à son ami Jim. A bien des égards, on retrouve dans les lettres et les fragments divers l'ironie et l'humour spécifiques de l'œuvre farrellienne, mais l'ouvrage aurait peut-être gagné en concision si quelques lettres, dont l'importance n'est pas capitale, n'avaient pas été prises en compte.

4 A cette réserve près, on ne peut que saluer le remarquable travail d'édition accompli ici, travail qui permettra au lecteur de connaître davantage un écrivain dont la trilogie ayant pour thème principal le déclin de l'Empire Britannique est devenue une référence en matière de roman historique, et a récemment été reéditée par The New York Review of Books. L'attribution en mai $2010 \mathrm{du}$ « Lost Man Booker Prize » au roman Troubles est une autre forme d'hommage à une œuvre hors du commun. A la suite de John Banville, Salman Rushdie ou Derek Mahon, chacun élira son roman favori, Troubles, The Siege of Krishnapur ou The Singapore Grip.

\section{AUTEURS}

\section{ELISABETH DELATTRE}

Université de l'Artois 